\title{
Sustained High Rates Of Job Creation And Destruction In Substate Economies
}

\author{
Christine Doyle-Burke, (E-mail: cdoyle@frc.mass.edu), M.A., Framingham State College \\ Maureen Dunne, (E-mail: mdunne@frc.mass.edu), M.B.A., Framingham State College \\ Marie McKinney, Ph.D., Framingham State College \\ Svetlana R. Grutman, B.S., Framingham State College \\ Michael Kreppel, B. A., Framingham State College
}

\begin{abstract}
Widely utilized net employment change statistics actually mask an extremely volatile process of job creation and destruction. In the past decade economists have addressed this problem by exploiting newly available longitudinal data series to estimate these job flows and the subsequent amount of job churning at the national, state and MSA level. This study is unique in that it uses an innovative technique to capture job flows within and between industries at the local area level where longitudinal BLS data series are not available.
\end{abstract}

The geographic unit of analysis in this paper is a Cohesive Commercial Statistical Area ${ }^{\mathrm{TM}}$ (CCSA), a substate aggregate of cities and towns sharing common economic interests but not a Metropolitan Statistical Area. The paper examines job flows in two very different Massachusetts substate economies: the MetroWest CCSA, a technology sensitive research and development economy, and the South Shore CCSA, a mature economy with a competitive edge in financial services. This study establishes that a sizable portion of disaggregated job flows can be captured at a substate level using available employment data. Building upon techniques used in earlier studies, the authors confirmed very high levels of employment volatility, "job churning”, in both substate regions.

The authors found that over two decades, job reallocation rates in MetroWest averaged 9\%, affecting one out of 11 jobs annually. The study traced the pattern of job creation and destruction over the course of local business cycles and found that both job creation and destruction existed during all phases of the business cycle. Although, as expected, job creation dominated the expansion phase and destruction dominated the contraction phase, the total amount of job reallocation (creation plus destruction) remained relatively stable through all stages of the business cycle. However, the composition of the job reallocation varied dramatically by stage of business cycle. A Job Replacement Ratio has been developed as a quick test to confirm economic expansion or contraction and to focus economic development efforts.

\section{Introduction}

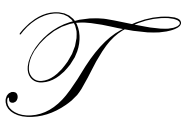

his paper addresses two important employment measurement issues. First, widely publicized national and state employment statistics usually focus on net employment change. These statistics often mask the underlying simultaneous process of job creation and job destruction. Second, national and state statistics obscure sizable differences in the nature of job creation and destruction at the local or substate level, an extremely volatile process. Adapting an innovative technique to examine job flows, the authors were able to capture a substantial portion of this volatility at the substate level. Quantifying the magnitude and direction of these flows is critical in pursuing optimal employment development policy at the local level ${ }^{1}$. 
The results of this study establish that net employment changes do not reflect the amount of job churning or volatility in a local economy and that economic regions within a state may differ in the rate of job destruction and the ability to create new jobs. The paper describes the method of estimating job churning using local area employment statistics and then compares the results for two contrasting regions within a state.

Initially this study focused on the MetroWest $\mathrm{CCSA}^{2}$, a technology sensitive substate economy in Massachusetts. Over two decades MetroWest experienced pronounced business cycles and major structural realignment on an unprecedented scale, yet generated very low average annual rates of net change. In a region rocked by economic turmoil, traditional measures like average annual net change repeatedly failed to grasp the magnitude of job losses or to identify the sources of job growth necessary for local economic development efforts to succeed.

Previous job churning research conducted at national and state levels offered an alternative model that disaggregated net job change into its components, job creation and job destruction, but use of the model required modification for substate use. The authors successfully developed a new methodology to measure job churning that quantified both job creation and job destruction for a substate region that is neither an MSA nor county-defined (MetroWest CCSA). A second substate region, the South Shore $\mathrm{CCSA}^{3}$, was also tested to ensure that the methodology would be adaptable to multiple substate regions with different industrial structures. For the first time economic data and analyses could capture job churning at this level, allowing economic development efforts to proceed.

\section{Previous Research}

Many studies have used the approach of disaggregating net job change into job creation and job destruction. However they have used different data sources, different means of aggregation, different time periods and different units of analysis. ${ }^{4}$ Among the earlier studies, Davis, Haltiwanger, and Schuh, focused on the U.S. manufacturing industry using 1972-1988 BLS Longitudinal microdata. ${ }^{5}$

\section{Figure 1: Substate regions}

Source: MERC, Framingham State College

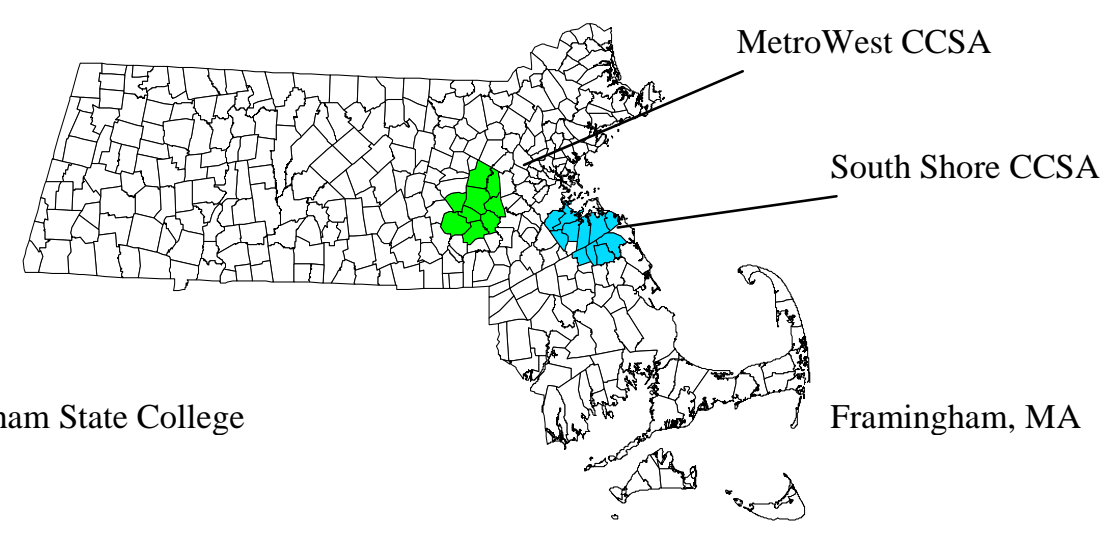


Following the approach used by Davis, Haltiwanger and Schuh, Bradbury examined job flows for total nonagricultural employment in Massachusetts between 1988 and early 1999. ${ }^{6}$ An exclusive focus on net employment changes would have missed a substantial fraction of the gross job flows that occurred in Massachusetts between 1988 and 1999. ${ }^{7}$ Earlier work by Dunne and McKinney had examined the net employment changes in MetroWest, a small technology-sensitive region in eastern Massachusetts. ${ }^{8}$ They found differences between Massachusetts and MetroWest with respect to the severity and magnitude of cyclical and structural changes experienced in the 1980's and early 1990's. Because the intensity of these changes exceeded those experienced by Massachusetts, it was felt that MetroWest was a good candidate for the examination of job flows at the substate regional level.

\section{Substate Regions}

This study examines job flows in two Massachusetts substate regions, the MetroWest and South Shore CCSAs, between 1980-2001. The MetroWest CCSA includes nine towns located between Boston and Worcester, Massachusetts with a Census 2000 population of 183,800, and 106,000 jobs, 3.2\% of Massachusetts employment. ${ }^{9}$ The South Shore CCSA includes eleven communities located between Boston and Brockton, Massachusetts with a Census 2000 population of 315,000, and 154,000 jobs, almost 5\% of Massachusetts employment ${ }^{10}$. Both substate regions experienced similar cyclical changes with a very severe recession sandwiched between two expansionary periods. (Figure 2)

Figure 2: Cyclical Employment Change, 1980-2001

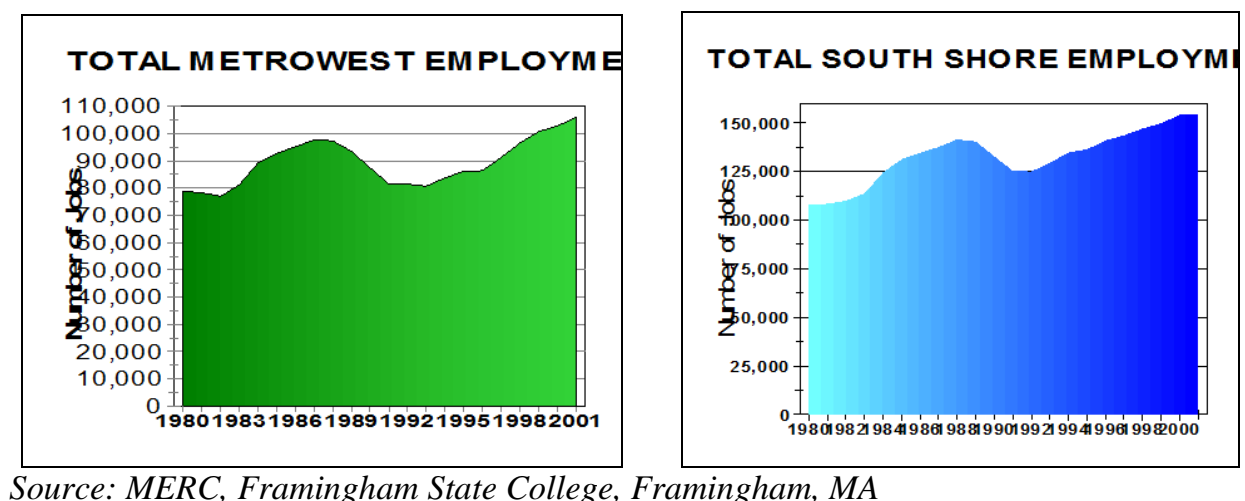

Source: MERC, Framingham State College, Framingham, MA

However, the MetroWest and South Shore CCSAs differ strikingly from each other in industrial structure. Not only did they differ in 2001, both regions had reinvented themselves undergoing massive structural realignment over the previous two decades. (Figure 3)

Between 1980 and 2001, annual net change for the MetroWest CCSA ranged from $+10 \%$ to $-7 \%{ }^{11}$. However, over the period, annual net change averaged only $1.5 \%$, a modest annual change. Similarly, annual net change for the South Shore CCSA ranged from $+10 \%$ to $-6 \%$, but over the period annual net change averaged $1.8 \% .^{12}$

Average annual net change failed to measure the economic turmoil and structural changes that had occurred in both substate regions. The classic, though intense, business cycles masked the dramatic Schumpeterian cycle of creative destruction. The 2001 economy in each region has a very different industrial structure than the economy of 1980. Tracking job flows between and within industries over the period is essential to understanding this critical process of economic regeneration. Job churning offered a better way to measure the job creation and job destruction that had occurred -- if current methodology could be adapted to these substate regions. 
Figure 3: Structural Realignment, 1980 vs. 2001

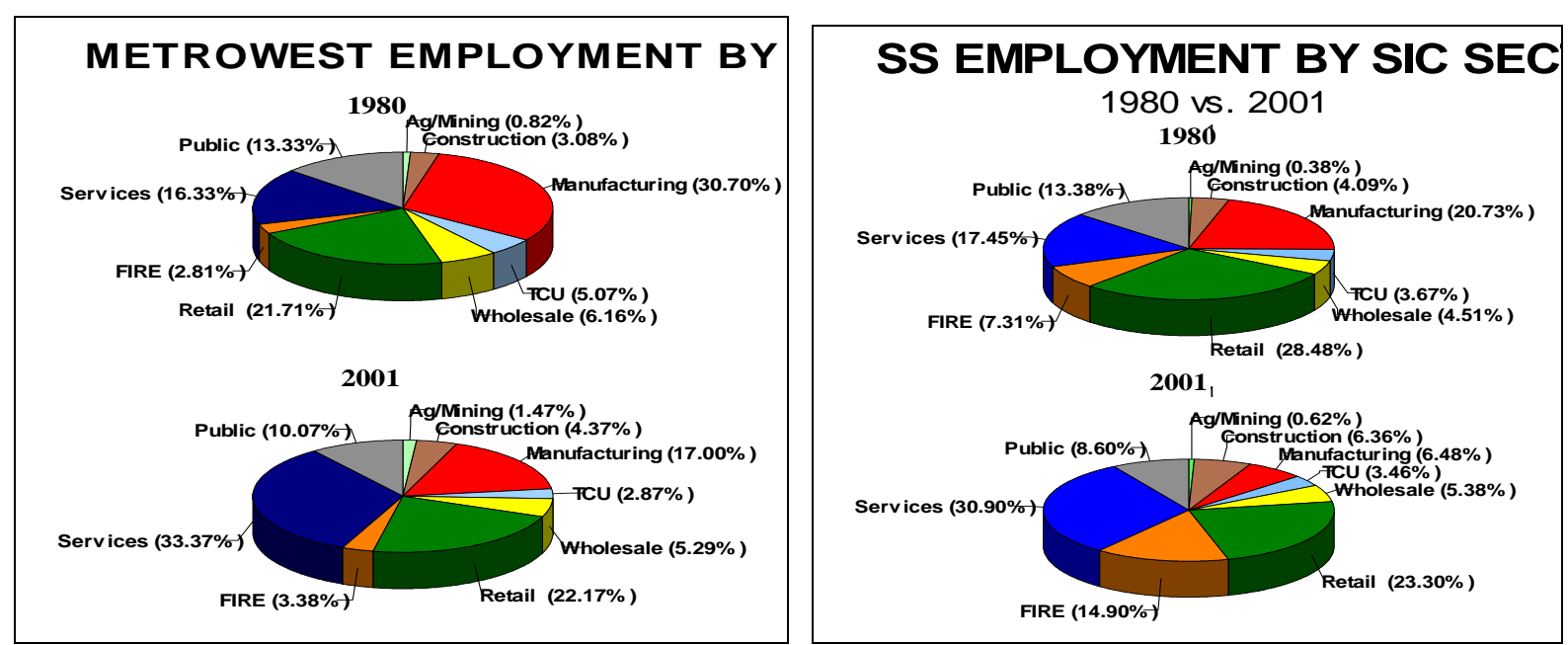

Source: MERC, Framingham State College, Framingham, MA

\section{Methodology}

This research uses a new methodology devised to estimate gross job flows. ${ }^{13}$ It is based on the traditional methodology of decomposing net job change into its components: job creation and job destruction. Job creation is the sum of employment gains at new and growing establishments. Job destruction equals the sum of employment losses at closing and shrinking establishments. Net job change is a measure of the net change in total employment from one year to the next. It is also equal to the difference between job creation and job destruction. In contrast, job reallocation is equal to the summation of job creation and job destruction. Because it measures the number of jobs that are either gained or lost in a given year, job reallocation is a more revealing indicator of economic activity, or churning, than the more commonly used net employment change. The Job Replacement Ratio is found by dividing job creation by job destruction. It serves as an index of the relative magnitude of creation and destruction.

Since the focus of this research was the measurement of economic activity in substate regions that do not coincide with MSAs or even county boundaries, the analysis began with annual employment data collected at the community (city or town) level. These data were obtained from the Massachusetts Division of Employment and Training (MA-DET) ES-202 series which tracks employment in those firms covered by the unemployment compensation insurance provisions. These data for Massachusetts communities are published annually and represent a census in the sense that they include all firms as opposed to a survey based on a sample. The time series used in the study covers 22 years (from 1980 through 2001).

The method used to determine these job flows involved calculating the year-to-year employment changes for each of the 9 major SIC industry classifications in each community (city or town) in the substate region. ${ }^{14}$ For example in the MetroWest region there are nine communities so this resulted in 81 industry/community variables. In the South Shore region, there are eleven communities, resulting in 99 industry/community variables.

This allowed the separation of the number of jobs created from those lost by subtracting employment in each year from that of the previous year for each individual industry/community observation. If the difference was greater than to zero, then these changes were recorded as job creation. If the difference was less than zero, then these changes were recorded as job destruction. Summing across communities by industry allowed for the determination of the total amount of job creation for each industry in MetroWest. For example, between 2000 and 2001 manufacturing employment increased from 15,426 to 18,013, a net job change in manufacturing employment in MetroWest of 2,587 jobs. When only those towns where manufacturing increased were counted, job creation 
totaled 3,320. When job creation numbers in all industries in MetroWest were added together, total job creation for the region was determined to be 6,480 . This was greater than the reported net change for the region of 3,210 by a factor of two.

Job destruction was calculated in an analogous manner. All the towns that reported net job destruction in manufacturing were totaled. In 2001, there were 733 manufacturing jobs destroyed in MetroWest. Hence, the net manufacturing change of 2,587 jobs was the result of 3,320 manufacturing jobs created minus 733 manufacturing jobs destroyed. When job destruction was summed across all industries a total of 3,270 MetroWest jobs were lost. Thus the net change in MetroWest employment of 3,210 was the result of the difference between 6,480 jobs created and 3,270 jobs destroyed. In 2001 a Job Replacement Ratio of 2, found by dividing total job creation by total job destruction, revealed that for every job lost, two new jobs were created.

Job reallocation was then obtained by adding total job creation and total job destruction. Across all industries, job reallocation totaled 9,750. This was greater than the net change $(3,210)$ by a factor of three. Actual values were then converted to percentage changes by dividing the gross changes by employment in the previous year. These results are summarized in Appendix 1, Table $1 .{ }^{15}$

\section{Results}

As expected, the traditional method of measuring economic activity by relying on annual average net employment changes masked the amount of churning occurring in the MetroWest job market. As seen in Table 1, the annual average rate of net employment growth of $+1.5 \%$ for the 22 -year period actually resulted from a $5.3 \%$ annual average rate of job creation offset by a $3.8 \%$ rate of job destruction. Thus, this methodology reveals that new and expanding establishments added jobs while dying and contracting establishments were cutting jobs, economic activity not revealed by conventional analysis. To better understand how conventional methods have failed to describe MetroWest, this section summarizes the magnitude and variability of job flows by looking in more detail at job creation, job destruction and job reallocation.

\section{Job Creation}

As seen in Figure 4 and Column 2 of Table 1, the annual rate of gross job creation was large, averaging $5.3 \%$. Job creation occurred in all years and was highly variable, ranging from a low of $0.9 \%$ in 1991 in the middle of the 1987-93 recession to a high of $10.1 \%$ in 1984. The most recent rate of job creation was $6.3 \%$ in 2001 . The coefficient of variation of $43 \%$ for the two-decade period reveals a high degree of volatility.

\section{Job Destruction}

As seen in Figure 4 and Column 3 of Table 1, the annual rate of gross job destruction was also large, averaging $3.8 \%$ per year. Job destruction occurred in every year and was also highly variable. The lowest rate, $0.1 \%$, occurred during the mid-80's expansion while the highest rate, $8.3 \%$, occurred in 1990 during the recession. In 2001, the most recent year in the series, 3.2\% of the jobs were destroyed. With a coefficient of variation of $60 \%$ for the 1980 to 2001 period, the data reveals that job destruction was even more volatile than job creation.

\section{Job Reallocation}

Looking at job creation and job destruction together gives a more complete picture as to why the conventional "net employment change" method failed to reveal the dynamic nature of the MetroWest job market. Job reallocation, the sum of job creation and job destruction, averaged over 9\% between 1980-2001 as shown in Column 4 in Table I. Thus, about 1 out of every 11 jobs in MetroWest was either created or destroyed in an average year. Even the minimum rate of job reallocation of $6.3 \%$ in 1982 revealed that 1 in 16 jobs was affected. In 1993, $14.5 \%$ or 1 out of every 7 jobs rolled over. 
Figure 4: Substate Job Creation and Destruction, 1980 - 2001

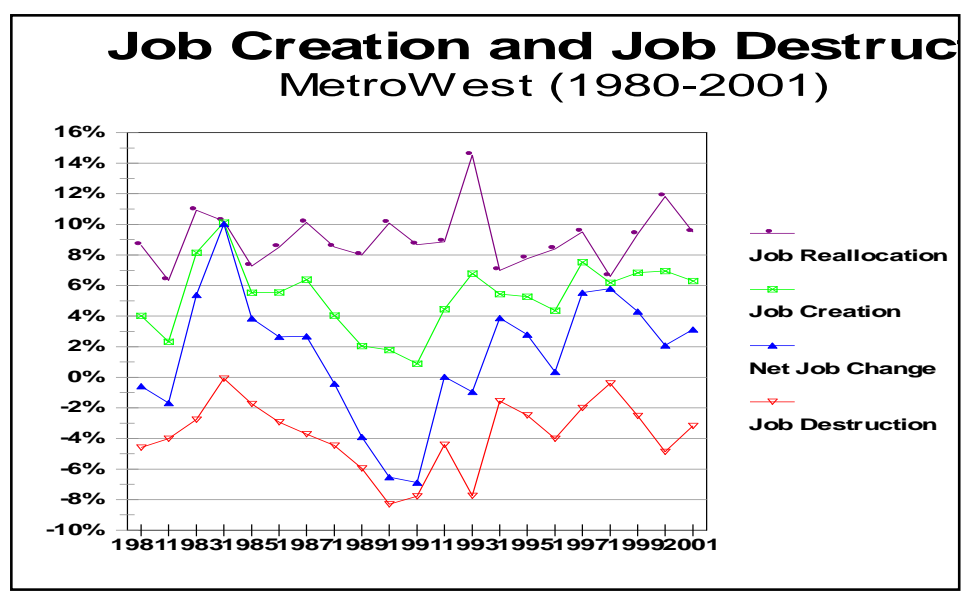

Figure 4 shows both the job creation and job destruction components of job reallocation. This rate of job reallocation remained at a consistently high level for the two-decade period. The two components dovetailed to produce a relatively flat and high rate of job reallocation. It follows that the coefficient of variation of $21 \%$ was much smaller than that for the rates of job creation and job destruction, showing that this overall measure of labor market activity was much more stable than either of its components.

The traditional method of measuring economic activity by relying on the annual average net employment change $(+1.5 \%)$ understated the amount of churning actually going on in the MetroWest labor market. This $+1.5 \%$ was actually the result of a 5.3\% annual average rate of job creation offset by a 3.8\% rate of job destruction. Over the more than two decades from 1980 through 2001, the MetroWest economy added about 27,000 jobs, on net ${ }^{16}$. Upon closer examination of gross yearly flows, it was revealed that about 98,000 jobs were created and 71,000 jobs were destroyed. A total of 169,000 jobs had been affected as the region reinvented itself.

To further emphasize the magnitude of the economic volatility revealed using this methodology, it is instructive to look at column 7 of Table I, the ratio of gross job reallocation to net employment change. This ratio, ranging from 1.02 to 248.7 , had a median of 2.8. In a typical year the rate of job reallocation was three times the rate of net change. In some years the ratio reveals very little difference $(1984,1991,1998)$, whereas there are years when the turmoil difference is great $(1981,1988,1992,1996)$. In fact, in 1992, the headlines may have reported a net increase of only 29 jobs in MetroWest. However, it is much more revealing to know that this was the result of 3,620 newly created jobs offset by 3,591 destroyed jobs. Thus, 249 times as many jobs were affected as reported in the headlines.

\section{Job Replacement Ratio}

The Job Replacement Ratio (JRR), found by dividing job creation by job destruction, shows whether employment was expanding or contracting over time ${ }^{17}$. The ratio ranged form a low of 0.11 in 1991, indicating that only $1 / 10^{\text {th }}$ of a job was created for each job lost, to a 1984 high when more than 177 new jobs were created for each job lost. The average Job Replacement Ratio over the 22-year period was 7.8. The average Job Replacement Ratio during the expansion years, indicated by a Job Replacement Ratio greater than one, reveals that nearly 11 times as many jobs were created than destroyed. The average during the contraction years, indicated by a Job Replacement Ratio less than one, reveals that 6/10ths of a job was created for each job destroyed.

\section{Stages of Business Cycle}

The decomposition of net job change into its components allows comparison of job creation and job destruction during the phases of the business cycle. As shown in Figure 5, during both the five-year expansion in the 1980s and the expansion that began in 1993, the number of jobs created well exceeded the number of jobs lost in MetroWest. 
In each time period, the gross Job Replacement Ratio showed that, in absolute numbers, job creation was more than double job destruction. In other words, for each job lost during the region's two most recent expansions, more than two jobs were created.

Figure 5: MetroWest Job Replacement Ratio (JRR) During Business Cycles

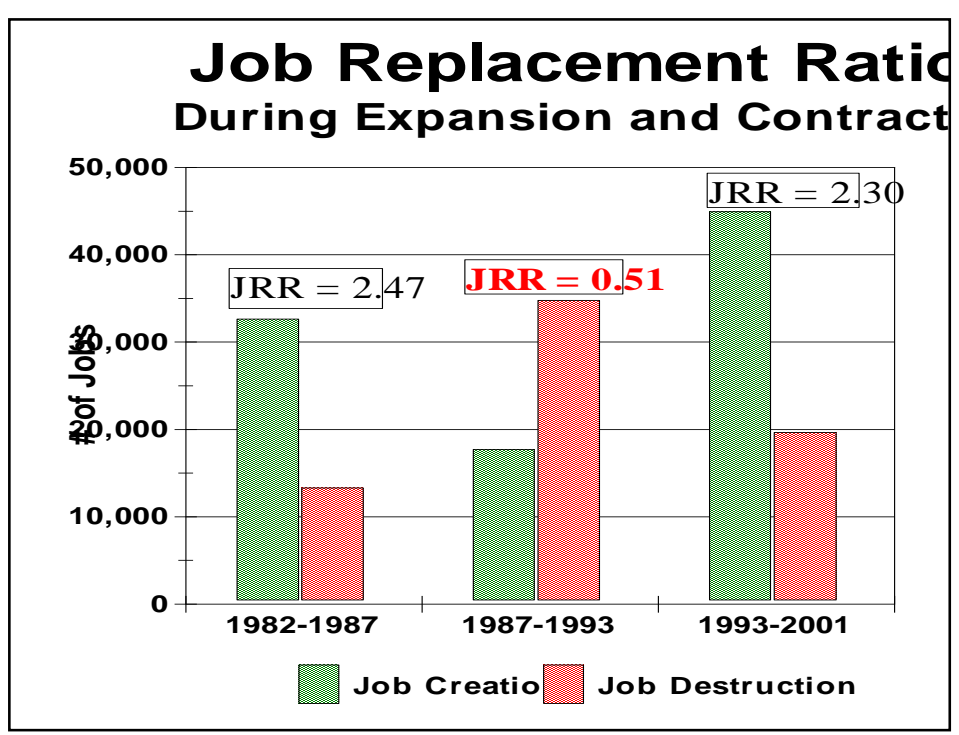

However, the region's most recent period of contraction shows the opposite of what was found in both expansions. Absolute job destruction well exceeded job creation as job destruction rose while job creation fell. A gross Job Replacement Ratio of 0.51 between 1987 and 1993 indicates that absolute job creation was only half of absolute job destruction over the period. Roughly 17,500 jobs were created while over 34,000 were lost. Source: MERC, Framingham State College, MA

\section{Comparison of Substate Regions}

The new methodology also allows comparison of the critical variables between substate regions. As stated above, between 1980 and 2001, annual net change for the MetroWest CCSA ranged from $+10 \%$ to $-7 \%$. However, over the period, annual net change averaged only $1.5 \%$, a modest annual change. Similarly, annual net change for the South Shore CCSA ranged from $+10 \%$ to $-6 \%$, but over the period annual net change averaged $1.8 \% .^{18}$

Job creation, job destruction and job reallocation rates were also determined for the South Shore CCSA (Appendix 1, Table 2). The average annual rate of job creation was $4.6 \%$, the average annual rate of job destruction was $2.8 \%$ and the average annual rate of job reallocation was $7.4 \%$. On average over two decades, 1 out of every 13 jobs in the South Shore was either newly created or destroyed, a rate of reallocation slightly lower than that experienced in MetroWest.

As shown in Figure 6, MetroWest rates of job creation and job destruction often exceeded those found in the South Shore CCSA. Economic development policies for MetroWest and South Shore must address the differences in these variables. On a practical note, identifying these differences in job creation and job destruction will allow economic development policies to be individually tailored to a specific substate region, rather than relying on a one-size-fits-all approach for all substate regions.

\section{Conclusion}

This study shows that sub-state regions such as CCSAs can be subject to highly volatile periods of employment growth and contraction. This volatility is reflected in the large estimates of job reallocation in both the technology driven MetroWest CCSA and the more traditional South Shore CCSA. In periods when public attention is often focused on the problem of job loss, widely utilized net employment change statistics often mislead because they fail to account for the persistence of the process of job creation, which usually is present even during periods of substantial job destruction. Misrepresenting the dynamic nature of economic activity by ignoring job creation often results in poorly informed policy initiatives especially at the local level. Making information about job creation explicit helps discourage the focus on salvaging old, often obsolete jobs, and instead will encourage policies that nurture and encourage the creation of new jobs. 
It is especially important that measures of job creation, destruction and reallocation be available for the formation of economic development policy at the local level. This study demonstrates that this information can be approximated at the sub-state for relatively small economic regions. Although this paper describes job churning in the context of total employment, this method also produces estimates of job creation, destruction, and reallocation at the 1-digit SIC level.

Figure 6: Comparison of Job Creation and Job Destructions By Substate Region:
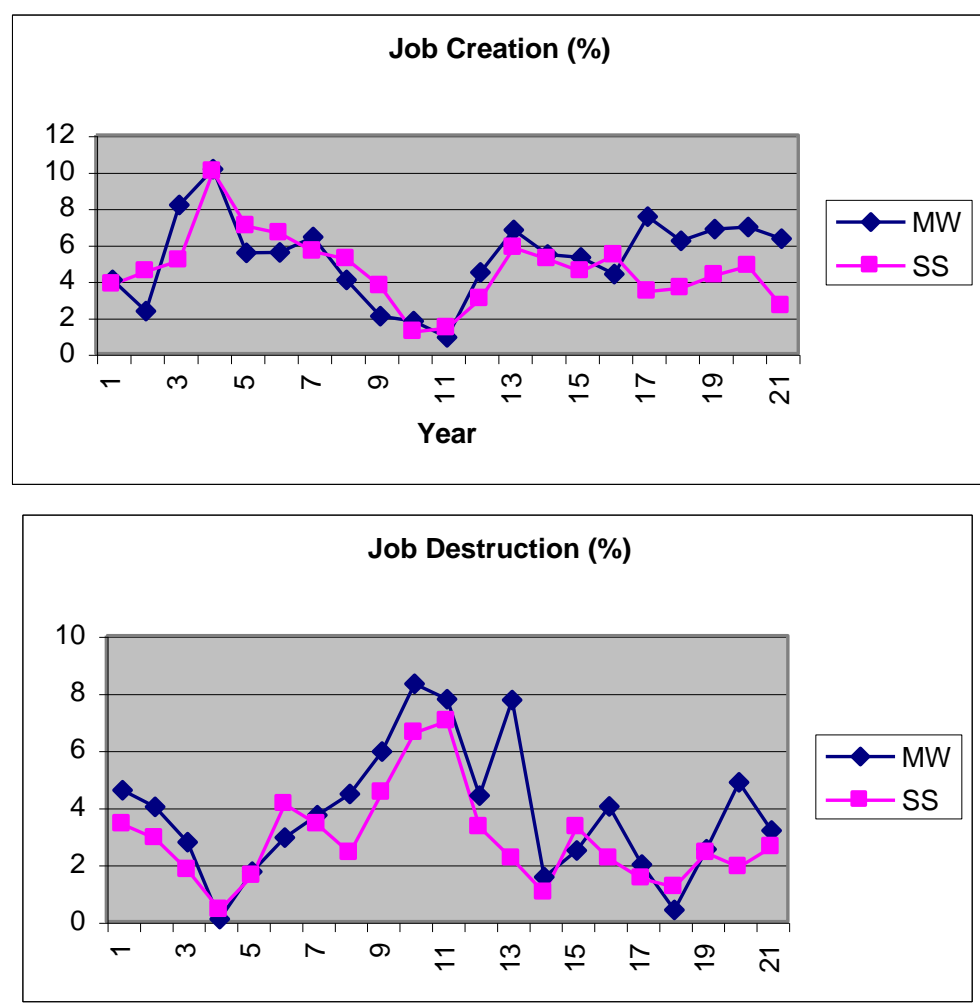

Source: MERC, Framingham State College, Framingham, MA 


\section{Appendix I}

Table I

\begin{tabular}{|c|c|c|c|c|c|c|c|}
\hline $\begin{array}{c}\text { METROWEST } \\
\text { CCSA }\end{array}$ & $\begin{array}{c}\text { Job Creation } \\
\text { Rate }\end{array}$ & $\begin{array}{c}\text { Job Destruction } \\
\text { Rate }\end{array}$ & $\begin{array}{c}\text { Net Job } \\
\text { Change Rate }\end{array}$ & $\begin{array}{c}\text { Job Reallocation } \\
\text { Rate }\end{array}$ & JC/NC & JR/NC & $\begin{array}{c}\text { JC/JD= } \\
\text { JR Ratio }\end{array}$ \\
\hline $1980-81$ & $4.03 \%$ & $-4.59 \%$ & $-0.58 \%$ & $8.63 \%$ & -6.98 & 14.93 & 0.88 \\
\hline $1981-82$ & $2.33 \%$ & $-4.01 \%$ & $-1.68 \%$ & $6.34 \%$ & -1.38 & 3.77 & 0.58 \\
\hline $1982-83$ & $8.15 \%$ & $-2.77 \%$ & $5.38 \%$ & $10.92 \%$ & 1.51 & 2.03 & 2.95 \\
\hline $1983-84$ & $10.13 \%$ & $-0.09 \%$ & $10.04 \%$ & $10.21 \%$ & 1.01 & 1.02 & 117.39 \\
\hline $1984-85$ & $5.53 \%$ & $-1.74 \%$ & $3.87 \%$ & $7.27 \%$ & 1.43 & 1.88 & 3.18 \\
\hline $1985-86$ & $5.56 \%$ & $-2.93 \%$ & $2.64 \%$ & $8.49 \%$ & 2.11 & 3.22 & 1.90 \\
\hline $1986-87$ & $6.40 \%$ & $-3.72 \%$ & $2.68 \%$ & $10.12 \%$ & 2.39 & 3.78 & 1.72 \\
\hline $1987-88$ & $4.05 \%$ & $-4.46 \%$ & $-0.41 \%$ & $8.51 \%$ & -9.92 & 20.85 & 0.91 \\
\hline $1988-89$ & $2.05 \%$ & $-5.95 \%$ & $-3.90 \%$ & $8.00 \%$ & -0.53 & 2.05 & 0.34 \\
\hline $1989-90$ & $1.78 \%$ & $-8.31 \%$ & $-6.53 \%$ & $10.10 \%$ & -0.27 & 1.55 & 0.21 \\
\hline $1990-91$ & $0.89 \%$ & $-7.78 \%$ & $-6.89 \%$ & $8.68 \%$ & -0.13 & 1.26 & 0.11 \\
\hline $1991-92$ & $4.45 \%$ & $-4.41 \%$ & $0.04 \%$ & $8.86 \%$ & 124.83 & 248.66 & 1.01 \\
\hline $1992-93$ & $6.79 \%$ & $-7.74 \%$ & $-0.95 \%$ & $14.53 \%$ & -7.11 & 15.23 & 0.88 \\
\hline $1993-94$ & $5.44 \%$ & $-1.56 \%$ & $3.88 \%$ & $7.00 \%$ & 1.40 & 1.80 & 3.49 \\
\hline $1994-95$ & $5.28 \%$ & $-2.48 \%$ & $2.80 \%$ & $7.76 \%$ & 1.89 & 2.77 & 2.13 \\
\hline $1995-96$ & $4.36 \%$ & $-4.02 \%$ & $0.34 \%$ & $8.38 \%$ & 12.74 & 24.47 & 1.09 \\
\hline $1996-97$ & $7.53 \%$ & $-1.99 \%$ & $5.53 \%$ & $9.52 \%$ & 1.36 & 1.72 & 3.78 \\
\hline $1997-98$ & $6.20 \%$ & $-0.40 \%$ & $5.80 \%$ & $6.60 \%$ & 1.07 & 1.14 & 15.44 \\
\hline $1998-99$ & $6.83 \%$ & $-2.53 \%$ & $4.31 \%$ & $9.36 \%$ & 1.59 & 2.17 & 2.71 \\
\hline $1999-00$ & $6.96 \%$ & $-4.87 \%$ & $2.09 \%$ & $11.83 \%$ & 3.33 & 5.65 & 1.43 \\
\hline $2000-01$ & $6.31 \%$ & $-3.18 \%$ & $3.12 \%$ & $9.49 \%$ & 2.02 & 3.04 & 1.98 \\
\hline Average & $5.29 \%$ & $-3.79 \%$ & $1.50 \%$ & $9.08 \%$ & & 7.8 \\
\hline
\end{tabular}

Source: MERC, Framingham State College, Framingham, MA

Table 2

\begin{tabular}{|c|c|c|c|c|c|c|c|}
\hline $\begin{array}{c}\text { SOUTH SHORE } \\
\text { CCSA }\end{array}$ & $\begin{array}{c}\text { Job Creation } \\
\text { Rate JC }\end{array}$ & $\begin{array}{c}\text { Job Destruction } \\
\text { Rate JD }\end{array}$ & $\begin{array}{c}\text { Net Job Change } \\
\text { Rate NC }\end{array}$ & $\begin{array}{c}\text { Job Reallocation } \\
\text { Rate JR }\end{array}$ & JC/NC & JR/NC & $\begin{array}{c}\text { JC/JD= } \\
\text { JR Ratio }\end{array}$ \\
\hline $1980-81$ & $3.8 \%$ & $-3.4 \%$ & $0.34 \%$ & $7.14 \%$ & 11.12 & 20.96 & 1.13 \\
\hline $1981-82$ & $4.5 \%$ & $-2.9 \%$ & $1.52 \%$ & $7.46 \%$ & 3.00 & 4.92 & 1.56 \\
\hline $1982-83$ & $5.1 \%$ & $-1.8 \%$ & $3.35 \%$ & $6.90 \%$ & 1.53 & 2.06 & 2.89 \\
\hline $1983-84$ & $10.0 \%$ & $-0.4 \%$ & $9.60 \%$ & $10.37 \%$ & 1.04 & 1.08 & 26.13 \\
\hline $1984-85$ & $7.0 \%$ & $-1.6 \%$ & $5.35 \%$ & $8.62 \%$ & 1.30 & 1.61 & 4.27 \\
\hline $1985-86$ & $6.6 \%$ & $-4.1 \%$ & $2.53 \%$ & $10.65 \%$ & 2.61 & 4.21 & 1.62 \\
\hline $1986-87$ & $5.6 \%$ & $-3.4 \%$ & $2.19 \%$ & $8.92 \%$ & 2.54 & 4.08 & 1.65 \\
\hline $1987-88$ & $5.2 \%$ & $-2.4 \%$ & $2.82 \%$ & $7.56 \%$ & 1.84 & 2.68 & 2.19 \\
\hline $1988-89$ & $3.7 \%$ & $-4.5 \%$ & $-0.82 \%$ & $8.13 \%$ & -4.47 & -9.94 & 0.82 \\
\hline $1989-90$ & $1.2 \%$ & $-6.6 \%$ & $-5.39 \%$ & $7.72 \%$ & -0.22 & -1.43 & 0.18 \\
\hline $1990-91$ & $1.4 \%$ & $-7.0 \%$ & $-5.55 \%$ & $8.43 \%$ & -0.26 & -1.52 & 0.21 \\
\hline $1991-92$ & $3.0 \%$ & $-3.3 \%$ & $-0.30 \%$ & $6.31 \%$ & -10.19 & -21.37 & 0.91 \\
\hline $1992-93$ & $5.8 \%$ & $-2.2 \%$ & $3.52 \%$ & $8.01 \%$ & 1.64 & 2.28 & 2.57 \\
\hline $1993-94$ & $5.2 \%$ & $-1.0 \%$ & $4.17 \%$ & $6.23 \%$ & 1.25 & 1.49 & 5.05 \\
\hline $1994-95$ & $4.5 \%$ & $-3.3 \%$ & $1.21 \%$ & $7.77 \%$ & 3.73 & 6.45 & 1.37 \\
\hline $1995-96$ & $5.4 \%$ & $-2.2 \%$ & $3.25 \%$ & $7.64 \%$ & 1.67 & 2.35 & 2.48 \\
\hline $1996-97$ & $3.4 \%$ & $-1.5 \%$ & $1.91 \%$ & $4.90 \%$ & 1.78 & 2.56 & 2.28 \\
\hline $1997-98$ & $3.6 \%$ & $-1.2 \%$ & $2.37 \%$ & $4.82 \%$ & 1.52 & 2.03 & 2.94 \\
\hline $1998-99$ & $4.3 \%$ & $-2.4 \%$ & $1.89 \%$ & $6.74 \%$ & 2.28 & 3.57 & 1.78 \\
\hline $1999-00$ & $4.8 \%$ & $-1.9 \%$ & $2.90 \%$ & $6.73 \%$ & 1.66 & 2.32 & 2.51 \\
\hline $2000-01$ & $2.6 \%$ & $-2.6 \%$ & $0.01 \%$ & $5.24 \%$ & 184.09 & 367.32 & 1.00 \\
\hline Average & $4.6 \%$ & $-2.8 \%$ & $1.76 \%$ & $7.44 \%$ & & & 3.12 \\
\hline
\end{tabular}

Source: MERC, Framingham State College, Framingham, MA 


\section{End Notes}

${ }^{1}$ For this study the unit of analyses is Cohesive Commercial Statistical Area ${ }^{\mathrm{TM}}$ or CCSA, smaller substate regions with separate identifiable economies. These CCSAs typically do not adhere to county or MSA boundaries so data must be aggregated up from the community (city or town) level to create the substate regional database. Particularly true in Massachusetts where county lines led to the term "gerrymandering", counties are being phased-out as political units, and the Boston NECMA extends beyond state lines.

2 The MetroWest CCSA includes nine towns: Ashland, Framingham, Holliston, Hopkinton, Natick, Sherborn, Southborough, Sudbury and Wayland representing $1 / 30^{\text {th }}$ of Massachusetts' employment.

3 The South Shore CCSA includes eleven communities: Abington, Braintree, Cohasset, Hanover, Hingham, Milton, Norwell, Quincy, Randolph, Rockland, Weymouth representing $1 / 20^{\text {th }}$ of Massachusetts employment.

${ }^{4}$ Many recent studies have appeared using newer BLS Longitudinal microdata containing information on all private and public establishments. T. R. Pivetz, M. A. Searson, and J. R. Spletzer, "Measuring job and establishment flows with BLS longitudinal microdata," Monthly Labor Review, April 2001, pp.13-20, introduced this data along with $4^{\text {th }}$ quarter 1999 U.S. results. Researchers are beginning to study job flows at the state and MSA level. See P. A. Hardiman and R. Holden, "Dynamic Job Gains and Losses in California; Underlying Economic Change," Working Paper \#2003-01, California Employment Development Department, Labor Market Information Division, March 7, 2003, for a survey of recent work.

${ }^{5}$ S. J. Davis, J. C. Haltiwanger, and S. Schuh, Job Creation and Destruction, (Cambridge, MA, MIT Press, 1996).

${ }^{6}$ K. L. Bradbury, "Job Creation and Destruction in Massachusetts: Gross Flows Among Industries," New England Economic Review, September/October 1999, pp. 33-52.

${ }^{7}$ Her work was prompted by the fact that the Massachusetts economy had experienced wide swings in employment in the 1990s, losing over 10 percent of existing jobs in the 1990-91 recession (which began in MetroWest in 1987) and not surpassing its pre-recession job peak until early 1998. She found that gross job flows were large compared with net employment changes resulting in an average job creation rate of $2.1 \%$, an average job destruction rate of $1.8 \%$ and an average gross job reallocation rate of $3.9 \%$.

${ }^{8}$ M. Dunne and M. McKinney, MetroWest: Supply-Side Changes and Rapid Sectoral Shift in a Small Open Economy, MetroWest Economic Research Center, Framingham State College, 1994.

${ }^{9}$ See M. Meaney and J. Truffa, MetroWest CCSA Labor Force Study, June 2003, p.2, and C. Doyle-Burke, M. Dunne, et al., MetroWest CCSA Economic Profile 2003, June 2003, p. 11.

${ }^{10}$ M. Meaney and J. Truffa, South Shore CCSA Labor Force Study, June 2003, p. 2.

${ }^{11}$ C. Doyle-Burke, M. Dunne, et al., MetroWest CCSA Economic Profile 2003, June 2003, p. 36.

${ }^{12}$ C. Doyle-Burke, M. Dunne, et al., South Shore CCSA Economic Profile 2004, p. 19.

${ }^{13}$ When referring to gross job flows, this paper is focusing on employment changes at the place of work. These changes are the result of the opening or closing of an establishment, or the expansion or contraction of its workforce. This paper is not dealing with worker flows measured as the hiring or separating activities of employees.

14 The relatively small size of the MetroWest economy allowed us to construct consistent time series data only at the major industrial level. Because confidentiality laws prohibit publication of data where there are fewer than 3 firms in a classification or where 1 firm accounts for more than $80 \%$ of employment within a classification, too many classified entries at the 2-digit level prevented construction of a reliable time series below the major industrial classification level

${ }^{15}$ Although this paper refers to total job creation and total job destruction, several levels of activity are missing. For example, in a given year one manufacturing plant in Framingham may lay off a worker and another manufacturing plant in Framingham may hire a worker - same town, same industrial category - but this change would not be caught. Also, within a single establishment, one job might be created while another is destroyed: a filing clerk is fired and a computer network supervisor is hired. This job destruction and creation would not be captured. Finally, the available data allows us to look only at annual job flows since quarterly and monthly data are not available at the community level.

${ }^{16}$ C. Doyle-Burke, M. Dunne, et al., MetroWest CCSA Economic Profile 2003, June 2003, p. 11.

${ }^{17}$ If the job replacement ratio is greater than zero and less than one, job destruction dominates and net change is negative. If the job replacement ratio is equal to one, job creation equals job destruction and net change is zero. If the job replacement ratio is greater than one, job creation dominates and net change is positive.

${ }^{18}$ C. Doyle-Burke, M. Dunne, et al., South Shore CCSA Economic Profile 2004, p. 23. 